\title{
Article
}

Arq Neuropsiquiatr 2010;68(2):252-257

\section{Olfactory function and Parkinson's disease in Southern Brazil}

\author{
Ricardo Santin', Vicente Faraon Fonseca' , Cristina Birlen Bleil', \\ Carlos R.M. Rieder ${ }^{3}$, Arlete Hilbig ${ }^{1,2}$
}

\begin{abstract}
The idiopathic Parkinson disease (IPD) is traditionally diagnosed by motor signs, but nonmotor symptoms and signs are frequent and may help in the clinical diagnosis. Purpose: To evaluate the olfactory function in Brazilian healthy subjects, patients with early-onset PD (EOPD) and late-onset PD (LOPD) using the Sniffin' Sticks odor-identification test (SST). Method: We studied 70 patients with IPD (19 EOPD and 51 LOPD) and 70 controls matched for gender, age and years of schooling. Subjects with dementia and loss of smell for other reasons were excluded. Results: The SST showed a significant difference $(p<0.001)$ between groups: control groups (12.0 \pm 0.3$)$, EOPD (8.3 \pm 0.7$)$, and LOPD $(6.7 \pm 0.4)$ when the groups were adjusted for gender, age, disease duration, and years of schooling. Conclusion: Both groups of IPD patients presented olfactory impairments, but those whose symptoms started before 45 years-old (EOPD) had better sense of smell than the LOPD patients.
\end{abstract}

Key words: Parkinson disease, olfactory function, sniffin' sticks.

\section{Função olfatória e doença de Parkinson no sul do Brasil}

\section{RESUMO}

A doença de Parkinson idiopática (DPI) tradicionalmente é diagnosticada pelos sinais motores, porém os sinais e sintomas não-motores são freqüentes. Objetivo: Avaliar a função olfatória em sujeitos brasileiros saudáveis e em pacientes com doença de Parkinson precoce (DPP) e doença de Parkinson tardia (DPT) utilizando o teste Sniffin' Sticks (TSS) de identificação de odores. Método: Setenta pacientes com DPI (19 DPP e 51 DPT) e 70 controles pareados para as variáveis gênero, idade e anos de escolaridade foram estudados. Foram excluídos sujeitos com demência e/ou perda de olfato por outros motivos. Resultados: O TSS mostrou uma diferença significativa $(p<0,001)$ entre os grupos controle $(12,0 \pm 0,3)$, DPP $(8,3 \pm 0,7)$ e DPT $(6,7 \pm 0,4)$ quando os grupos foram ajustados para sexo, idade, duração da doença e anos de escolaridade. Conclusão: Pacientes com DPI apresentam redução do olfato, sendo mais importante entre aqueles com DPT. A disfunção olfatória pode ser uma ferramenta muito útil no diagnóstico de DPI.

Palavras-chave: doença de Parkinson, função olfatória, sniffin sticks.

\section{Correspondence \\ Arlete Hilbig \\ Rua Sarmento Leite 245 \\ 90050-170 Porto Alegre RS - Brasil \\ E-mail: hilbiga@terra.com.br}

Received 14 September 2009

Received in final form 26 October 2009

Accepted 9 November 2009
Idiopathic Parkinson disease (IPD) is the second most common neurodegenerative disorder. Although traditionally considered as a degeneration of dopaminergic neurons of substantia nigra pars compacta $(\mathrm{SNc})$, it has been proved to be a much more spread disease with involvement of multiple systems. Braak et al. ${ }^{1}$, studying
110 brains from patients in different stages of IPD, suggested that the progression of the pathological process, with the presence of Lewy bodies and neurites, starts with the involvement of brainstem nuclei and the olfactory system, involving the olfactory bulb and anterior olfactory nuclei. From there, the disease would involve the 
brainstem progressively before reaching the $\mathrm{SNc}$, when motor signs usually appear. This pathological description has found support in clinical studies. Usually patients seek medical attention due to motor signs, but non-motor symptoms and signs are frequent and some of them, especially smell problems and sleep disturbances, might even precede motor signs ${ }^{2}$.

As there is no biological marker and the clinical diagnosis of IPD is probabilistic and based on a set of symptoms and signs, clinicians have to look for as many signs as possible to build up the diagnosis. Smell dysfunction may be a very helpful tool in an diagnosis of IPD. There are different smell tests currently in use in Europe and North America ${ }^{3}$, but few studies of olfactory function are available in other regions ${ }^{4}$.

The aim of this study was provide normative data of olfactory test for south Brazilian healthy population using the Sniffin' Stick odor identification test and compare the results with an IPD population. We also compared the olfactory function on subgroups of IPD: early-onset PD (EOPD) and late-onset PD (LOPD).

\section{METHOD}

\section{Sample}

We performed a case-control study and a smell test in 140 subjects distributed in two different groups:

\section{Group 1}

Seventy subjects with clinical diagnosis of IPD, based on the UK Parkinson's disease Society Brain Bank's crite$\mathrm{ria}^{5}$, were assessed from movement disorders outpatient clinics at Universidade Federal de Ciências da Saúde de Porto Alegre (UFCSPA), Hospital de Clínicas de Porto Alegre (HCPA), and private clinics. This group was further separated in two subgroups: patients with symptoms starting before 45 years-old (early-onset PD - EOPD, $\mathrm{n}=19$ ); and patients whose symptoms started after 45 years-old (late-onset PD - LOPD, $n=51$ ). All IPD patients were given a smell test during the on period and were classified via the Hoehn and Yahr (H\&Y) rating scale and motor part (III) of the Unified Parkinson Disease Rating Scale (UPDRS III).

\section{Group 2}

Seventy healthy volunteers were recruited from other outpatient clinics and the community. They were matched to IPD patients for gender, age and, years of schooling. We had selected people without neurological diseases, no family history of parkinsonism, and no complains of smell problems.

\section{Olfactory test}

The smell test was performed by means of the Sniffin' Sticks odor-identification test (SST) (Burghart Medizintchnik, Gemany), commercially available, validated and largely used in Europe. The test consists of sixteen pens filled with common odorants: orange, leather, cinnamon, peppermint, banana, lemon, licorice, turpentine, garlic, coffee, apple, cloves, pineapple, rose, anise, and fish. The pens have approximately $14 \mathrm{~cm}$ in length and can be used for up to one year, according to manufacturer. The test was translated to Portuguese and had been used before on a Brazilian population ${ }^{6}$.

During the test, the experimenter had to remove the cap and place the tip of the pen $2 \mathrm{~cm}$ from both nostrils of the patients. They were free to sample the odors as often as necessary until they were able to identify the odorant from a list of four options given by the examiner for each pen. If they were not able to identify it, they had to guess (forced multiple choice task identification test). The interval between each odorant was at least 30 seconds. The test was performed in a quiet, well-ventilated room and we did not employ any self-administered test.

Both the IPD and the control subjects were submitted to mini-mental examination prior to the test to exclude cognitive dysfunctions. Subjects with respiratory symptoms during the previous two weeks before the test were excluded from both groups, and we also assessed smoking status and the presence of chronic rhinitis and sinusitis. All had agreed to participate, after full explanation about the study, and signed a consent form. The study was approved by UFCSPA Ethical Committee $\left(\mathrm{n}^{\circ} 428 / 07\right)$.

\section{Statistical analysis}

The statistical analysis was performed through the SPSS 15.0 Software. We used the chi-square, 2-way ANOVA, and Pearson's correlation test for comparison of qualitative, quantitative versus qualitative and quantitative variables, respectively. To compare SST scores among groups, we have used the ANCOVA Model to adjust for the effects of sex, age, disease duration and schooling.

\section{RESULTS}

Both groups had thirty-eight male subjects (54.3\%) and thirty-two female (45.7\%). The baseline characteristics of control subjects. EOPD and LOPD are shown in Table 1. There was no difference between the groups for sinusitis $(\mathrm{p}=0.27)$ and rhinitis (0.50). Subjects with previous history of sinusitis or rhinitis did not have different scores from those without these problems $(\mathrm{p}=0.36$ and $\mathrm{p}=0.10$, respectively). There was a significant difference $(\mathrm{p}=0.02)$ for smoking between control group (zero smokers and 11 ex-smokers) and the IPD groups (seven smokers and 13 ex-smokers), but we did not find a difference in the SST score between ex-smokers and non-smokers $(\mathrm{p}=0.15)$ in controls or among smokers, ex-smokers and non-smokers in IPD patients ( $\mathrm{p}=0.27)$.

The control group $(n=70)$ had a mean score of SST of 
Table 1. Comparison of baseline characteristics and Sniffin' Sticks test among control and Parkinson disease subjects.

\begin{tabular}{lcccc}
\hline Characteristic & $\begin{array}{c}\text { Control } \\
\mathrm{n}=70\end{array}$ & $\begin{array}{c}\text { EOPD } \\
\mathrm{n}=19\end{array}$ & $\begin{array}{c}\text { LOPD } \\
\mathrm{n}=51\end{array}$ & $\mathrm{p}$ \\
\hline Age, years & $63.8 \pm 10.5$ & $45.0 \pm 5.6$ & $67.8 \pm 9.0$ & $<0.001^{[1]}$ \\
Male sex, No. (\%) & $38(54.3)$ & $9(47.4)$ & $29(56.9)$ & $0.778^{[2]}$ \\
Schooling, years & $6.9 \pm 4.5$ & $8.9 \pm 4.4$ & $5.4 \pm 3.5$ & $0.006^{[1]}$ \\
Duration of disease, years & - & $9.7 \pm 5.9$ & $5.9 \pm 4.2$ & $0.005^{[1]}$ \\
Age of onset, years & - & $35.3 \pm 7.4$ & $61.9 \pm 9.5$ & $<0.001^{[1]}$ \\
First symptom & - & & & $0.06^{[2]}$ \\
Tremor & - & $10(53)$ & $43(84)$ & \\
Bradykinesia & - & $8(42)$ & $5(10)$ & $3(6)$ \\
Rigidity & - & $1(5)$ & $6(12)$ & $0.08^{[2]}$ \\
Familiar history & - & $6(32)$ & $2.2 \pm 0.9$ & $0.09^{[1]}$ \\
Hoehn \& Yahr & - & $2.6 \pm 0.6$ & $16.7 \pm 7.6$ & $0.64^{[1]}$ \\
UPDRS III & $12.0 \pm 2.2$ & $9.6 \pm 2.3$ & $6.3 \pm 2.8$ & $<0.001^{[1]}$ \\
SST crude & $12.0 \pm 0.3$ & $8.3 \pm 0.7$ & $6.7 \pm 0.4$ & $<0.001^{[3]}$ \\
SST adjusted* & & &
\end{tabular}

Data are presented as mean \pm SD or mean \pm SE (in the adjusted model) and counts (percentages). SST: Sniffin' Sticks test; EOPD: early onset Parkinson disease; LOPD: early onset Parkinson disease; p: statistical significance; ${ }^{[1]}$ ANOVA; ${ }^{[2]}$ Chi-square; ${ }^{[3]}$ ANCOVA model adjusting for age, sex, disease duration and years of schooling. ${ }^{*}$ Multiple contrasts: control vs. EOPD: $p<0.001$, control vs. LOPD: $p<0.001$; EOPD vs. LOPD: $p=0.032$.

$12.0( \pm 2.2$ SD) (range: 6-16; median: 12). Through a multiple regression analysis, we found that age $(\mathrm{p}=0.001)$, years of education $(\mathrm{p}=0.037)$, and gender $(\mathrm{p}=0.049)$ were inde-

Table 2. Distribution of correct identification of odors among control, EOPD and LOPD.

\begin{tabular}{lccc}
\hline Odors of SST & $\begin{array}{c}\text { Control } \\
\mathrm{n}=70(\%)\end{array}$ & $\begin{array}{c}\text { EOPD } \\
\mathrm{n}=19(\%)\end{array}$ & $\begin{array}{c}\text { LOPD } \\
\mathrm{n}=51(\%)\end{array}$ \\
\hline Orange (1*) & $65(93)$ & $12(63)$ & $31(61)$ \\
Fish (16) & $64(91)$ & $17(89)$ & $31(61)$ \\
Coffee (10) & $63(90)$ & $15(79)$ & $23(45)$ \\
Banana (5) & $60(86)$ & $16(84)$ & $32(63)$ \\
Garlic (9) & $59(84)$ & $16(84)$ & $28(55)$ \\
Peppermint (4) & $58(83)$ & $12(63)$ & $21(41)$ \\
Pineapple (13) & $57(81)$ & $9(47)$ & $20(39)$ \\
Cloves (12) & $55(79)$ & $13(68)$ & $23(45)$ \\
Anise (15) & $55(79)$ & $13(68)$ & $17(33)$ \\
Cinnamon (3) & $55(79)$ & $9(47)$ & $13(25)$ \\
Rose (14) & $54(77)$ & $14(74)$ & $12(24)$ \\
Licorice (7) & $50(71)$ & $11(58)$ & $11(22)$ \\
Lemon (6) & $50(71)$ & $10(53)$ & $19(37)$ \\
Leather (2) & $39(56)$ & $8(42)$ & $18(35)$ \\
Turpentine (8) & $39(56)$ & $7(37)$ & $23(45)$ \\
Apple (11) & $14(20)$ & $0(0)$ & $7(14)$ \\
\hline Data are prented & & &
\end{tabular}

Data are presented in counts (percentages). SST: Sniffin' Sticks test; EOPD: early onset Parkinson disease; LOPD: early onset Parkinson disease. ${ }^{*} T$ he number indicates the sequence of odor in the SST. pendently correlated with the SST score. Females had a mean score around one point above males $(12.5 \pm 1.7$ and $11.5 \pm 2.5$ respectively). There was a negative correlation with age: for each increased year of age there was a 0.08 point decrease in the SST score. The identification of hits of each odor is show in Table 2.

Most IPD patients ( $\mathrm{n}=70)$ had a mild to moderate disease (H\&Y 1.0 to 3.0). The EOPD developed their symptoms at an average age of $35.3( \pm 7.4)$ years and the LOPD group, at $61.9( \pm 9.5)$ years $(\mathrm{p}<0.001)$. There was no difference between the subgroups in disease severity, although the EOPD group had a longer disease duration $(9.7 \pm 5.9)$ than the LOPD $(5.9 \pm 4.2)(\mathrm{p}=0.005)$. The average score in the SST of the IPD group was $7.2( \pm 3.0)$ (range: $2-14)$. The family history of IPD was positive in 6 patients (13\%) of the LOPD and in other 6 patients (31.6\%) of the EOPD, without a significant difference $(\mathrm{p}=0.084)$.

There was a significant difference $(p<0.001)$ between the IPD patients and the control group in the average adjusted SST score. Both the EOPD and the LOPD subgroups showed worse smell scores than the controls $(\mathrm{p}<0.001$ and $\mathrm{p}<0.001)$ in the adjusted SST score mean. There was also a difference between subgroups of IPD, the EOPD patients showing better sense of smell $(8.3 \pm 0.7 \mathrm{SE})$ than those with LOPD $(6.7 \pm 0.4 \mathrm{SE})(\mathrm{p}=0.032)$ in the adjusted SST score (Table 1). As there was also a significant difference on sex, age at examination, disease duration, and years of schooling between subgroups, we performed a multiple regression analysis and found that the 
Table 3. Sensibility and specificity for different cut-off SST scores in the EOPD and LOPD.

\begin{tabular}{cccc}
\hline Subgroup & Cut-off Score & Sensibility & Specificity \\
\hline EOPD & $\leq 11$ & $78.9 \%$ & $61.4 \%$ \\
EOPD & $\leq 10$ & $63.2 \%$ & $78.6 \%$ \\
EOPD & $\leq 9$ & $36.8 \%$ & $85.7 \%$ \\
EOPD & $\leq 8$ & $26.3 \%$ & $94.3 \%$ \\
LOPD & $\leq 10$ & $90.2 \%$ & $78.6 \%$ \\
LOPD & $\leq 9$ & $88.2 \%$ & $85.7 \%$ \\
LOPD & $\leq 8$ & $76.5 \%$ & $94.3 \%$ \\
LOPD & $\leq 7$ & $66.7 \%$ & $95.7 \%$ \\
\hline
\end{tabular}

SST: Sniffin' Sticks test; EOPD: early onset Parkinson disease; LOPD: early onset Parkinson disease.

difference in SST score among the IPD subgroups were not due to these variables, but independently related with the subgroup (early or late onset PD), being better among those with EOPD.

We also found that olfactory dysfunction was different depending upon the first symptom, being better among those who presented bradykinesia at first. Using subgroup stratification, we found that the difference is due to subgroups: EOPD had usually started the disease with bradykinesia while the LOPD had mainly tremor as the first symptom.

The cut-off score in the SST that better discriminated IPD from the controls in our population was different depending upon the age of onset. For LOPD patients, nine or less correct answers (of 16) give us a score with sensibility of $88.2 \%$ and specificity of $85.7 \%$ for the IPD diagnosis. If we are trying to establish a diagnosis of EOPD, we should consider a higher score, with ten or less correct answers (of 16) showing sensibility of $63.2 \%$ and specificity of $78.6 \%$ (Table 3). A particular patient with mild signs of parkinsonism and SST below the chosen cut-off would have 17 times more chance of belonging to the IPD group instead of the control group.

\section{DISCUSSION}

The sense of smell has been under evaluated on clinical practice: physicians usually do not give importance to smell problems and patients are often unaware of their smell dysfunction and do not complain about it. However, this sensation plays an important role in quality of life: it determines the flavor of food and drinks and provides protection against dangerous and spoiled substances. The olfactory loss may also indicate an ongoing neurodegenerative disease. Many authors have drawn attention to smell problems in disorders such as Parkinson's disease? Alzheimer's disease and mild cognitive impairment ${ }^{8,9}$. Therefore, a routine evaluation of smell function can be a very helpful tool in the clinical diagnosis of these diseases, or at least a "red flag" for closer evaluation and follow-up in asymptomatic subjects.

Many tests are available to detect olfactory loss, but there are cross-cultural differences, which imply we cannot use the results of one study for every population. The most used tests are the University of Pennsylvania Smell Identification Test (UPSIT) and the Sniffin' Stick test (SST). UPSIT is a one-way scratch and sniff test used in North America since 1984; SST is a reusable and portable test currently in use mainly in European countries and has been standardized and validated since 1995. Both tests evaluate the olfactory function by means of olfactory threshold, discrimination, and identification. As far as we know, there is no commercially available smell test in Brazil.

A population of IPD patients and healthy Brazilian subjects had been tested for odor identification through cross-cultural UPSIT ${ }^{6,13}$ and SST ${ }^{6}$. Both tests were performed with patients from São Paulo and did not separate EOPD of LOPD. Our sample comes from very south of Brazil, with different culture and environment. Quagliato et al. studied a sample of 75 controls and 50 IPD patients whose mean age were 64.8 years, and found a sensitivity of $80 \%$ at UPSIT test ${ }^{13}$. Silveira-Moriyama et al. analyzed 118 controls and 106 IPD patients, with a mean age of 61.3 years. The UPSIT sensitivity was $82.1 \%$ and its specificity was $83.5 \%$; the SST sensitivity was $81.1 \%$ and the specificity was $89.0 \%{ }^{6}$. Our LOPD group showed similar results (sensibility of $88.2 \%$ and specificity of $85.7 \%$ ).

Using the SST to test our population, most subjects claimed to be familiar to all odors presented. Among 16 odors, only turpentine and apple were poorly identified by the controls and also did not show differences between the controls and the IPD patients. Previous studies showed similar results ${ }^{6,13}$ and then, these odors should probably be excluded when testing the Brazilian population.

In healthy populations, we confirmed an age-related decrease of the olfactory function and a better sense of smell among women. Hummel et al., 2007, studying more than 3,000 healthy subjects in Germany, showed age and sex effects in olfactory ability; and an age-related decrease of olfactory function has been suggested in numerous previous studies ${ }^{3}$. The best odor performance occurs between 20 and 40 years and begins to decline steadily after this age ${ }^{14}$. Although regularly observed, loss of the olfactory function is not inevitable and age is not the cause of this loss. It has been shown that "successfully aged elderly" also exhibit a normal olfactory function ${ }^{15}$. Otherwise, it was also shown that the olfactory bulb is one of the earliest sites where Alzheimer's and Parkinson's types of changes appear in the brain ${ }^{16,17}$. Considering the presence of smell dysfunction in asymptomatic elderly populations and a high prevalence of neurodegenerative dis- 
eases, this finding might be a predictor of further development of neurodegenerative diseases, which can have a long pre-clinical phase. Hyposmia seems to precede the development of IPD ${ }^{2}$ but further studies are needed to address the risk of neurodegenerative diseases in asymptomatic elderly populations with smell dysfunctions.

The sense of smell is better developed in females. The reasons for gender differences are also unknown and have been speculated to be attributed to various factors including hormonal effects, verbal skills or congenital factors $^{3}$. A stereological study ${ }^{18}$ of the human olfactory bulb showed that the number of tyrosine hydroxylase $(\mathrm{TH})$ positive cells (dopaminergic cells) in females is half than that found in males. As TH cells appear to be inhibitory in the olfactory bulb, probably decreasing the inputs from the olfactory epithelium to the olfactory cortex, the lack of inhibition may be one reason.

Olfactory dysfunctions in the IPD include impairments in both odor identification and discrimination performance. Boesveldt et al. ${ }^{10}$, studying 404 IPD patients and 150 controls tested with the SST, showed that use of the odor identification test is a good and sufficient tool to discriminate IPD patients from controls with no increase in specificity and/or sensibility if one adds discrimination and/or identification tests. The impairment of odor identification is more prevalent than a deficit on odor discrimination, although odor discrimination seems to worsen, increasing the duration of the disease. The multiple-choice identification test, in which the subject has to identify the stimulus from a list of odor names, is the most sensitive and specific procedure ${ }^{11}$. As the subject is forced to select one answer in each case, some correct answers could be given by chance, but it has been shown that the probability of more than seven correct answers by chance is very low (less than $5 \%$ ), and scores lower than seven should be considered as anosmia ${ }^{12}$.

There was a significant difference in the SST scores between controls and IPD patients. The presence of a smell dysfunction had a high sensibility (EOPD 63.2\%; LOPD 88.2\%) and specificity (EOPD 78.6\%; LOPD 85.7\%) for the IPD diagnosis in our population, suggesting that it may be very helpful when evaluating a particular patient with mild or atypical symptoms both for diagnosis and differential diagnosis. Other parkinsonian syndromes such as progressive supranuclear palsy, multiple system atrophy, and vascular Parkinsonism do not seem to have smell dysfunctions ${ }^{19,20}$. Also, patients with essential tremor, whose differential diagnosis with IPD may sometimes be very challenging, have a normal smell function ${ }^{21}$.

We also found that subjects whose symptoms started before the age of 45 years (EOPD) had a better sense of smell than those whose symptoms started after that. We studied a small population of EOPD and there was dif- ference between subgroups on age, education, and disease duration, but the age of onset did not depend on these variables in the SST score. From 19 patients with EOPD, twelve (63\%) scored in normal range, while 12\% of LOPD had a normal smell test. Then, in order to improve diagnosis specificity, we must use a higher cut-off among EOPD patients, which results in a lower diagnosis sensibility in this subgroup. We can just speculate about the reasons for this difference. Although olfactory loss is present in most IPD patients (up to 90\%), it is not present in all of them, IPD is a disease with many faces, or many different diseases. Diverse causes and mechanisms may initiate a process that seems to follow a similar pattern, both clinically and pathologically. It is possible that a subgroup with normal smell functions belongs to a specific subtype of disease, with a different cause and/or mechanism. It is also possible that, due to the individual variability and/or neuronal susceptibility, sites other than the olfactory tract may initiate the pathologic process and these individuals will not show any smell dysfunction.

There are clues pointing to environmental and genetic factors as a key for the IPD development. A study of patients with parkin mutations (Park 2), a monogenic form of EOPD, showed that the smell function is preserved in this population ${ }^{22}$. We did not perform genetic tests in the whole EOPD subgroup, but two siblings with a PINK 1 mutation in our group had normal smell tests (data not published). Patients with EOPD are more prone to have genetic forms of disease and data about olfactory function among genetic forms of EOPD are still lacking. Patients with LRRK2 mutations present olfactory dysfunction comparable to the IPD ${ }^{6}$, but this autosomal dominant Parkinsonism has a late disease onset and a similar phenotype of IPD.

Environmental toxins may also be responsible for the development of the Parkinsonian syndrome. The IPD has been proposed to be a primary olfactory disorder and the disease could start in the olfactory system with an alpha-synuclein conformational change generated in the olfactory epithelium, under the influence of environmental molecules and/or caused by genetic/molecular factors ${ }^{23,24}$. The pathogenic agent should have the ability to induce conformational transformation of a native $\alpha$-helix $\alpha$-synuclein into a pathological isoform, a $\beta$-sheet $\alpha$-synuclein, with the ability to form fibrils of Lewy bodies and Lewy neurites. The agent could be a prion-like protein, as recently suggested by Lerner and $\mathrm{Bagic}^{24}$. The sequence of brain changes in PD follows a specific and repeatable pattern, starting in the olfactory system and the dorsal motor vagus nucleus (enteric pathways), and then spreading through connections suggesting transneuronal transport to the upper parts of the brainstem and further to the cortical areas ${ }^{24}$. 
Although the Lewy body pathology has been demonstrated in olfactory areas by many authors, it is still unknown why IPD patients lose their smell function. In a pathological study of dopaminergic cells in the olfactory bulb of IPD and control subjects. Huisman et al. ${ }^{18}$ showed that IPD patients, both males and females, have the same amount of cells as control males. They suggest that hyposmia in PD is not just related with dopamine in the olfactory bulb.

ACKNOWLEDGMENTS - The authors thank Dr. Laura SilveiraMoriyama and Professor Andrew Lees (Queen Square Brain Bank, UK) for their comments and the Sniffin' Sticks material provided.

\section{REFERENCES}

1. Braak H, Tredici KD, Rüb U, de Vos RA, Jansen Steur EM, Braak E, Staging of brain pathology related to sporadic ParkinsonÅfs disease. Neurobiol Aging 2003;24:197-211.

2. Ross GW, Petrovitch $\mathrm{H}$, Abbott RD, et al. Association of olfactory dysfunction with risk for future ParkinsonÅfs disease. Ann Neurol 2008;63:167-173.

3. Hummel T, Kobal G, Gudziol H, Mackay-Sim A. Normative data for th ÅgSniffinÅf SticksÅh including tests of odor identification, odor discrimination, and olfactory thresholds: an upgrade based on a group of more than 3,000 subjects. Eur Arch Otorhinolaryngol 2007;264:237-243.

4. Double KL, Rowe DB, Hayes M, et al. Identifying the pattern of olfactory deficits in Parkinson disease using the brief smell identification test. Arch Neurol 2003;60:545-549.

5. Hughes AJ, Ben-Shlomo Y, Daniel SE, Lees AJ. What features improve the accuracy of clinical diagnosis in ParkinsonÅfs disease: a clinicopathologic study. Neurology 1992;42:1142-1146. Erratum in: Neurology 1992;42:1436.

6. Silveira-Moriyama L, Carvalho Mde J, Katzenschlager R, et al. The use of smell identification tests in the diagnosis of ParkinsonÅfs disease in Brazil. Mov Disord 2008;23:2328-2334.

7. Ansari KA, Johnson A. Olfactory function in patients with ParkinsonÅfs disease. J Chronic Dis 1975;28:493-497.

8. Christen-Zaech S, Kraftsik R, Pillevuit O, et al. Early olfactory involvement in AlzheimerÅfs disease. Can J Neurol Sci 2003;30:20-25.
9. Murphy C, Gilmore MM, Seery CS, Salmon DP, Lasker BR. Olfactory thresholds are associated with degree of dementia in AlzheimerÅfs disease. Neurobiol Aging 1990; 11:465-469.

10. Boesveldt $\mathrm{S}$, Verbaan $\mathrm{D}, \mathrm{Knol} \mathrm{DL}$, et al. A comparative study of odor identification and odor discrimination deficits in ParkinsonÅfs disease. Mov Disord 2008;23:1984-1990.

11. Eibenstein A, Fioretti AB, Lena C, Rosati N, Ottaviano I, Fusetti M. Olfactory screening test: experience in 102 Italian subjects. Acta Otorhinolaryngol Ital 2005;25:18-22.

12. Kobal G, Hummel T, Sekinger B, Barz S, Roscher S, Wolf S. ÅgSniffinÅf sticksÅh: screening of olfactory performance. Rhinology 1996;34:222-226.

13. Quagliato LB, Viana MA, Quagliato EM, Simis S. Olfactory dysfunction in ParkinsonÅfs disease. Arq Neuropsiquiatr 2007;65:647-652.

14. Kovács T. Mechanisms of olfactory dysfunction in aging and neurodegenerative disorders. Ageing Res Rev 2004;3:215-232.

15. Almkvist O, Berglund B, Nordin S. Odor detectability in successfully aged elderly and young adult. Reports from the Dept. of Psychology. Stockholm University 1992;744:1-12.

16. Kovács T, Cairns NJ, Lantos PL. Olfactory centres in AlzheimerÅfs disease: olfactory bulb is involved in early BraakÅfs stages. Neuroreport 2001;12:285-288.

17. Braak H, Del Tredici K, Bratzke H, Hamm-Clement J, Sandmann-Keil D, Rüb U. Staging of the intracerebral inclusion body pathology associated with idiopathic ParkinsonÅfs disease (preclinical and clinical stages). J Neurol 2002;249 (Suppl 3):S1-S5.

18. Huisman E, Uylings HBM, Hoogland PV. Gender-related changes in Increase of dopaminergic neurons in the olfactory bulb of Parkinson $\AA$ fs disease patients. Mov Disord 2008;23:1407-1413.

19. Doty RI, Golbe LI, McKeown DA, Stern MB, Lehrach CM, Crawford D. Olfac tory testing differentiates between progressive supranuclear palsy and idiopathic ParkinsonÅfs disease. Neurology 1993;43:962-965.

20. Wenning GK, Shephard B, Hawkes C, Petruckevitch A, Lees A, Quinn N. Olfactory function in atypical parkinsonian syndromes. Acta Neurol Scand 1995;91: 247-250.

21. Busenbark KL, Huber SJ, Greer G, Pahwa R, Koller WC. Olfactory function in essential tremor. Neurology 1992;42:1631-1632.

22. Verbaan $D$, Boesveldt $S$, van Rooden $S M$, et al. Is olfactory impairment in Parkinson disease related to phenotypic or genotypic characteristics? Neurology 2008;71:1877-1882.

23. Hawkes CH, Del Tredici K, Braak H. ParkinsonÅfs disease: a dual-hit hypothesis. Neuropathol Appl Neurobiol 2007;33:599-614.

24. Lerner A, Bagic A. Olfactory pathogenesis of idiopathic Parkinson disease revisited. Mov Disord 2008;23:1076-1084. 